\title{
TÉCNICAS DE MARKETING APLICADAS A BIBLIOTECA PADRE JOAQUIM COLAÇO DOURADO (UNIESP) ${ }^{1}$
}

\author{
Antônia Lucineide F. De Lima² \\ Reality Lab \\ professoraluhlima@gmail.com
}

Alessandro Pinon Leitão

Reality Lab

112prof1520@iesp.edu.br

Andressa da Silva Santos ${ }^{4}$

Reality Lab

a.94santos@gmail.com

Luiz Felipe da Silva Candido ${ }^{5}$

Reality Lab

luizphenix222@gmail.com

\section{Resumo}

O uso de ferramentas de marketing é de extrema importância para a disseminação de diversos serviços, devendose no cenário atual incluir tais ferramentas nos serviços de informação disponibilizados por bibliotecas. O artigo teve como objetivo descobrir e apresentar as técnicas de marketing aplicadas a Biblioteca Padre Joaquim Colaço Dourado, e sua importância para o bom desenvolvimento no atendimento de seus usuários por meio da construção e instalação de um planejamento de marketing que venha suprir as necessidades de seus gestores e usuários. $\mathrm{O}$ estudo se apresenta como uma pesquisa de campo qualitativa, e análise fundamentada na técnica do Discurso do Sujeito Coletivo. Os resultados apontam para o uso eficiente e eficaz das ferramentas de marketing, principalmente por meio das redes sociais, concluindo-se que os mesmos proporcionam atingir um maior público, com a possibilidade de obter resultados de pesquisas de satisfação, a divulgação de treinamentos, visibilidade dos serviços pelo site institucional, aumentando assim as visitas e interação nos eventos realizados pela instituição, maior participação da comunidade acadêmica, aumentando a comunicação e relacionamento interpessoal com toda comunidade, que é de fundamental importância para aumentar o números de pessoas atendidas pelo espaço da biblioteca.

Palavras-chave: Unidade de informação. Biblioteca. Marketing. Redes Sociais.

\section{MARKETING TECHNIQUES APPLIED TO PRIEST JOAQUIM COLAÇO DOURADO LIBRARIES (UNIESP/BR)}

\begin{abstract}
The use of marketing tools is extremely important for the dissemination of various services, and in the current scenario, such tools should be included in the information services provided by libraries. The article aimed to discover and present the marketing techniques applied to the Priest Joaquim Colaço Dourado Library, and its importance for the good development in serving its users through the construction and installation of a marketing plan that will meet the needs of its users. managers and users. The study presents itself as a qualitative field research, and analysis based on the technique of the Collective Subject Discourse. The results point to the efficient and effective use of marketing tools, mainly through social networks, concluding that they provide reach a larger audience, with the possibility of obtaining results from satisfaction surveys, the dissemination of training, visibility of services through the institutional website, thus increasing visits and interaction at events held by the institution, greater participation by the academic community, increasing communication and interpersonal relationships with the entire community, which is of fundamental importance to increase the number of people served by the library space.
\end{abstract}

Keywords: Information units. Libraries. Marketing. Social Media.

\footnotetext{
${ }^{1}$ Projeto de extensão aprovado pelo Edital 01/2017 da COOPEREC/UNIESP - Programa de Extensão edição 2020, com apoio da COOPERE/UNIESP

${ }^{2}$ Colaboradora Docente Reality Lab - Mestranda em Biblioteconomia - UFCA.

${ }^{3}$ Coordenador Reality Lab e Docente Uniesp - Centro Universitário.

${ }^{4}$ Colaboradora Reality Lab - Graduada em Gestão Comercial Uniesp.

${ }^{5}$ Colaborador Reality Lab - Graduando em Biblioteconomia UFPB
} 
INOVAÇÃO

\section{INTRODUÇÃO}

Em época de constantes mudanças voltívolas relativas, a agregação de valor e solidificação de uma marca, produto ou serviço conta com o auxílio de técnicas e estratégias de marketing que são essenciais para a sobrevivência das unidades de informação, em especial das bibliotecas universitárias, seja pela elaboração de um projeto de marketing ou instalação de um Sistema de Informação de Marketing (SIM).

Segundo Kotler e Bloom (1988, p. 2), marketing pode ser compreendido como o processo de “[...] análise, planejamento, implementação e controle de programas cuidadosamente formulados que visam proporcionar trocas voluntárias de valores ou utilidades dos mercados-alvo, com o propósito de realizar objetivos organizacionais.” Embasados por estes pensamentos, objetiva-se aqui apontar o uso do marketing por esta unidade de informação para sua valorização.

No que tange às unidades de informação, especialmente as bibliotecas universitárias, locus deste trabalho, as mesmas ofertam um benefício diferenciado no que concerne a forma de "consumo" da sua clientela/usuário, exigindo dos gestores bibliotecários um maior esforço para que os serviços ofertados consigam impactar seus usuários, serviços esses: empréstimo, disponibilização de espaços propícios a leitura, estudo e acesso a um maior número de informações por meio dos mais diversos suportes, sejam eles impressos ou digitais.

Diante das novas tecnologias e, consequentemente, as competências exigidas ao gestor bibliotecário, que se busca descobrir e apresentar as técnicas de marketing aplicadas à Biblioteca Padre Joaquim Colaço Dourado, e sua importância para o bom desenvolvimento no atendimento de seus usuários por meio da construção e instalação de um planejamento de marketing que venha suprir as necessidades de seus gestores e usuários.

\section{BIBLIOTECAS UNIVERSITÁRIAS}

A biblioteca universitária é um espaço basilar para assistir o discente durante sua formação, sendo sua principal missão como sistema de informação. Sua finalidade é armazenar, organizar e compartilhar conhecimento para auxiliar toda comunidade acadêmica.

O surgimento das bibliotecas universitárias se deu em conjunto com as instituições de ensino mais antigas. Nunes e Carvalho (2016, p.179), afirmam que “[...] as bibliotecas universitárias foram sendo criadas à medida que as primeiras universidades surgiam desde os Séculos X a XII, tais como as de Bolonha, Paris e Oxford.” A partir de doações de documentos 
pessoais de seus fundadores, os acervos nasceram dentro das instituições de ensino e foram tomando forma através das contribuições dos frequentadores.

Inserida neste quadro histórico, a biblioteca universitária desenvolveu-se ao longo dos séculos, buscando relacionar-se com a atualização do sistema acadêmico, seja adaptando seu acervo para acompanhar as modificações nas instituições de educação superior, seja aplicando variados tipos de organização bibliográfica, seja atendendo aos discentes, apesar do acesso limitado, seja mantendo o foco no próprio ofício conservando o conhecimento proveniente do que já possuía em seu acervo. Contudo, é durante o século XIX que a compreensão da relação da biblioteca universitária e alguns modelos de serviços surgiram (DIÓGENES; CUNHA, 2017).

A universidade ou instituição de ensino superior é a ponte pela qual o educando terá acesso ao acervo universitário. De acordo com Fujita (2005, p.100), “A Universidade promove a construção de conhecimento através da pesquisa, e realiza, por meio dos conteúdos curriculares, o contato do aluno com o conhecimento já construído.”

Com base nessa afirmação, compreende-se que a consulta ao material científico preservado pela biblioteca universitária é fundamental para o acadêmico desenvolver seus estudos. Nesse contexto, Fujita (2005, p.100) destaca que: “[...] a biblioteca universitária tornase consciente de sua função intermediadora realizando os processos documentários e preservando a informação para sua próxima transformação em conhecimento em uma espiral de evolução científica e tecnológica [...]"

Assente nesta elucidação, observa-se o padrão de looping, pois a informação compartilhada fomenta novos conhecimentos, os quais são lapidados e retornam ao seu imo. Hodiernamente, com o advento da internet, todos os setores da sociedade sofreram grande impacto, principalmente os sistemas de informação, gerando a necessidade de adaptações para amoldar-se a nova era digital.

Impelida pelo cenário atual, a biblioteca universitária passou a utilizar-se de novas ferramentas para continuar a cumprir seu papel. Sendo alguns dos aspectos explanados nas demais seções deste trabalho.

\subsection{MARKETING E SISTEMAS DA INFORMAÇÃO}

Sistema de Informações de Marketing (SIM), é um ramo da atuação empresarial que possui o objetivo de observar e coletar, utilizando e organizando as informações dos clientes, como: necessidades, desejos, renda, hábitos, preferências, etc. Para Kotler, 1998, p.56), 
"Somente empresas centradas nos clientes são verdadeiramente capazes de construir clientes, e não apenas produtos, e são hábeis em engenharia de mercados, não apenas em engenharia de produtos."

Em todo o caso, o SIM é fundamental para a construção de um marketing sólido e inteligente. Coletar informações precisas do cliente é o que contribui para o sucesso de qualquer organização ou empresa de qualquer segmento. A personalização e individualização é o principal objetivo do marketing em sistemas da informação. Segundo Revella (2015, p.2), “[...] a exigência do público é mais ou menos assim: Me diga o que eu quero saber e me ajude a encontrar a opção certa, em todas as etapas da minha decisão de compra, senão eu vou procurar em outro lugar".

O marketing é uma combinação de técnicas que visa o processo de troca dos dois lados: empresa e cliente. A promoção é utilizada nos canais da comunicação para informar sobre a existência de algo feito, com o objetivo de persuadir a compra os possíveis interessados.

Tratando-se dos centros de serviços da informação a exemplo de bibliotecas Araújo, Pinho Neto e Freire (2016, p.7) apontam que "[...] as atividades cotidianas das Bibliotecas Universitárias evidenciam novos mecanismos em detrimento da expansão tecnológica na sociedade e da rápida adoção por parte de seus usuários." Após o fenômeno da web, a biblioteca universitária também assumiu novos papéis que exige modernizar seus serviços tais como flexibilizar seus canais de atendimento, novos modelos e ferramentas de gestão, captação e manutenção de usuários através de métodos mercadológicos e ou estratégias de marketing.

O “Marketing é responsável pela administração das relações da empresa com o mercado. É o acompanhamento e estudo da concorrência, análise e seleção de mercados e clientes, definição de estratégia promocional.” (MAXIMIANO, 2000, p.240). Em geral, a promoção passada através da estratégia, deve conter informações claras e precisas, para esclarecer as dúvidas dos consumidores em relação ao serviço ou produto.

\section{METODOLOGIA}

Este estudo é parte integrante de um conjunto de pesquisas realizadas pelo grupo de Reality Pesquisa, que tem como objetivo realizar estudos nas áreas que fundamentam os pressupostos do marketing, administração, Cibercultura, Customer Relationship Management (CRM) e comportamento do consumidor, constituindo uma derivação de estudos e pesquisas a serem publicadas em ambiente acadêmico, eventos científicos municipais, estaduais e nacionais. Todas as pesquisas realizadas pela equipe discente e docente participante do projeto 
de pesquisa e extensão seguem parâmetros éticos e científicos em concordância com a resolução 466/12 do Conselho Nacional de Saúde do Ministério da Saúde, sendo a autorização de realização das mesmas aprovada desde a data de 31 de agosto de 2019 através de "Projeto guarda-chuva", que viabilizou o Parecer Consubstanciado do CEP de número CAEE 19919319.6.0000.5184.

O estudo se apresenta como uma pesquisa de campo qualitativa, tendo sua análise fundamentada na técnica do Discurso do Sujeito Coletivo (DSC), conceituada por Lefèvre F. e Lefèvre C. (2014) como a organização e representação de dados obtidos em depoimentos por meio de comunicação verbal, onde os aspectos a serem investigados podem estar fundamentados na teoria da Representação Social e seus pressupostos sociológicos, sob a forma de um ou vários discursos-síntese.

Para a exposição dos dados obtidos utilizando da técnica do DSC, o pesquisador precisa selecionar as informações de maneira individual, totalizando expressões-chave, ou seja, os trechos mais significativos das respostas, e a partir disso extrair as ideias centrais que representam a síntese do conteúdo discursivo manifestado nas expressões-chave e, a partir disso, construir com o material das expressões-chave das ideias centrais o discursos-síntese. (LEFÈVRE F.; LEFÈVRE C., 2000).

O corpus selecionado para a análise foram as gestoras e profissionais de marketing envolvidos no desenvolvimento de técnicas de marketing aplicadas à Biblioteca Padre Joaquim Colaço Dourado (UNIESP).

Para a coleta dos dados, foi utilizado de entrevista semiestruturada, utilizando de objeto de gravação para o registro das informações, após o esclarecimento feito pelo pesquisador com apresentação de conceitos abordados no roteiro, e assinatura do Termo de Consentimento Livre e Esclarecido (TCLE). Na entrevista foram abordados aspectos sobre o conhecimento e uso de técnicas de marketing como ferramentas que possam viabilizar os serviços ofertados e disseminação da informação.

\section{RESULTADOS}

Através dos resultados obtidos na pesquisa com a resposta do questionário enviado e preenchido pelo gestor na unidade de informação, a Biblioteca Universitária Padre Joaquim Colaço Dourado, pode-se identificar o perfil de seu gestor, a composição da sua equipe de marketing e compreensão da importância do marketing em sua visão para o bom 
desenvolvimento da biblioteca, bem como os serviços ofertados e ferramentas utilizadas para aplicação na unidade.

O questionário fora composto de 15 questões, sendo de estrutura aberta e múltipla escolha, sendo o mesmo divido em três sessões, a primeira corresponde a formação da equipe gestora e seu perfil levando em consideração sua formação acadêmica e sexualidade, a segunda sessão corresponde ao espaço da biblioteca e descrição dos serviços ofertados e a terceira questão ao entendimento da importância do marketing e sua aplicação na unidade.

\subsection{PRIMEIRA SESSÃO: GESTOR E EQUIPE}

Nesta primeira sessão foram realizados a apresentação de questões inerentes a formação acadêmica do gestor, bem como gênero e membros da equipe de marketing, no qual obteve-se seguintes resultados.

A equipe gestora da Biblioteca Universitária Padre Joaquim Colaço Dourado (UNIESP) tem em sua composição a presença de duas bibliotecárias, dais quais uma é a gestora da biblioteca, graduada em Biblioteconomia, mestrado em Gestão nas Organizações Aprendentes, e especialização em Gestão de Unidades de Informação.

Ao ser questionada sobre a formação da equipe de marketing da Biblioteca, constatouse a composição feita por dois profissionais, a primeira integrante da equipe é a própria gestora da biblioteca, e o segundo integrante um colaborador da equipe geral da biblioteca, vale salientar que este colaborador é Bibliotecário e possui especialização em Marketing.

Quando questionada sobre uma possível interferência do gestor nas ações que correspondem ao marketing desenvolvido na Biblioteca, a gestora afirma que em todas as ações que correspondem ao marketing, ela interfere e analisa cada prática a ser aplicada, sendo esta interferência feita não só por ela, mas também de toda equipe da biblioteca e o departamento de marketing da Instituição. Grogan (199, p. 52) afirma que o serviço de referência (SR) é “[...] a assistência pessoal prestada pelo bibliotecário aos leitores em busca de informações [...] é uma arte e a única maneira de apreendê-la é exercendo-a." O SR pode ser tanto presencial quanto virtual.

\subsection{SEGUNDA SESSÃO: ESPAÇO E SERVIÇOS}

Na composição do questionário, incidimos a constituição de duas perguntas no que corresponde a estrutura e espaço da biblioteca bem como dos serviços ofertados aos usuários 
no qual constatamos por meio da resposta de sua gestora uma estrutura de qualidade e eficiência, bem como uma ampla oferta de serviços.

A biblioteca é composta por uma estrutura moderna e nova do qual contam com ambientes projetados e inerentes ao bom funcionamento de todas as atividades realizadas pela instituição e a biblioteca, a saber: Salas de estudo individual e em grupo. Sala de Multimídia. Sala de Periódicos e TCC. Acervo geral. Terminais de Consulta ao Acervo. Cabines para Estudo. Sala de Leitura.

Os serviços ofertados pela biblioteca e sua equipe elencados pela gestora são: Atendimento ao cliente; Consulta presencial e on-line; Empréstimo domiciliar; Reservas e Renovação presencial e on-line; Levantamento bibliográfico; Catalogação na fonte; Atendimento e orientação para pesquisa as bases de dados e outras fontes; Normalização bibliográfica; Visitas dirigidas (sala de aula, auditório e nas dependências da Biblioteca); Disseminação seletiva da informação; Orientação para Elaboração de Trabalhos Acadêmicos; Referência (orientação ao usuário); Acesso à rede Wi-Fi; Divulgação e Marketing.

A composição do espaço e dos serviços ofertados, acabam por incidir sobre a avaliação do marketing da biblioteca ao ser questionada como a gestora avaliação a relação entre os usuários e a promoção do marketing da biblioteca a partir dos serviços ofertados e do espaço, fora relatado que:

Estamos ainda em fase de crescimento, acredito que falta alguns degraus para atingir o nosso objetivo. $G B$

\subsection{TERCEIRA SESSÃO: MARKETING E O SIM DA BIBLIOTECA}

Na terceira sessão do questionário, elucidou-se por meio das perguntas a compreensão e importância do marketing na unidade de informação, bem como as ferramentas utilizadas pela equipe para divulgação e promoção de suas ações por meio do marketing criado e a existência de um Sistema de Informação de Marketing (SIM).

Ao ser questionada sobre a importância do marketing e a existência de um SIM e sua importância dentro da biblioteca para o bom desenvolvimento das ações da biblioteca a gestora afirmou de forma positiva a importância do marketing e a existência de um SIM. Na perspectiva de Cintra (2010, p. 9), “[...] marketing são as atividades sistemáticas de uma organização humana, voltadas para a busca e a realização de trocas com seu meio ambiente, visando a benefícios específicos."

Diante da afirmativa e entendimento da importância do uso do marketing e da existência de um SIM, questionou-se a gestora sobre o que a motivou, e sua equipe, a criação 
do SIM na Biblioteca, onde a mesma nos informou que não havia uma resposta exata para a pergunta feita.

Ao ser questionada sobre quais ferramentas a Biblioteca utiliza para disseminação da informação e das ações a serem desenvolvidas na Biblioteca, a gestora nos informou que as principais ferramentas de divulgação são: o uso de murais informativos, cartazes de divulgação, folder com orientações, por meio do disparo de e-mail aos usuários bem como o uso de redes sociais como o Facebook e o Instagram.

Vale salientar, que mediante o questionário aplicado pode-se perceber o bom desenvolvimento das ações de marketing realizados pela Biblioteca, e a consciência e importância destas ações, sendo respondido de maneira positiva pela gestora ao questionamos da importância do uso de técnicas de marketing diante das novas tecnologias, ao qual a mesma afirmou ser de fundamental importância.

\begin{abstract}
A informação bruta, crua e que muitas vezes não é absorvida com eficácia por muitos, precisa ser lapidada e organizada. Célebre função do profissional da informação, que além de obter toda a técnica, precisa procurar conduzir a informação por um caminho para que ela tenha seu devido uso pelo usuário final (SILVA; SALCEDO, 2017, p.24.).
\end{abstract}

Ao final do questionário, indagou-se a gestora quais são as principais técnicas de marketing aplicadas pela biblioteca, onde nos fora respondido que as técnicas utilizadas são: atingir o público pelas redes sociais, pesquisas de satisfação, treinamentos, visibilidade dos serviços pelo site institucional, visitas dirigidas, interação nos eventos dos cursos, interação com os professores em reuniões e eventos, e a comunicação e relacionamento interpessoal com toda comunidade que é de fundamental importância.

Ressalta-se a compreensão e entendimento da gestora sobre a importância do marketing e criação de um SIM, bem como seu empenho em ofertar um serviço de qualidade aos usuários por meio da aplicação das técnicas de marketing, tendo em consideração a valorização dos serviços ofertados aos seus clientes/usuários.

\title{
5 CONSIDERAÇÕES FINAIS
}

O uso de ferramentas de marketing é de extrema importância para a disseminação de diversos serviços, devendo no cenário atual incluir tais ferramentas também os serviços de informação disponibilizados pelas bibliotecas. Nesta seara, buscou-se no presente artigo descobrir e apresentar o uso do marketing em uma unidade de informação de uma biblioteca 
universitária, bem como as ferramentas utilizadas pela equipe para divulgação e promoção de suas ações por meio do marketing criado, sendo pautada a existência e experiência de um Sistema de Informação de Marketing (SIM) dentro de tal espaço.

Diante da coleta de dados ficou perceptível que a gestora da unidade de informações conta com uma equipe de marketing, e que utiliza de diversos meios e canais para a disseminação dos serviços prestados, sendo as principais ferramentas de divulgação: o uso de murais informativos, cartazes de divulgação, folder com orientações, por meio do disparo de $e$ mail aos usuários, bem como o uso de redes sociais como o Facebook e o Instagram.

Ao ser questionada sobre qual os principais resultados das ferramentas e mídias utilizadas obteve-se como respostas que é possível: atingir o público pelas redes sociais, sendo ainda possível obter resultados de pesquisas de satisfação, a divulgação de treinamentos, visibilidade dos serviços pelo site institucional, aumentando assim as visitas e interação nos eventos realizados pela instituição, maior participação da comunidade acadêmica, discente, docentes e demais funcionários, aumentando a comunicação e relacionamento interpessoal com toda comunidade que é de fundamental importância para aumentar o números de pessoas atendidas pelo espaço da biblioteca. 


\section{ARTIGO}

INOVAÇÃo

\section{REFERÊNCIAS}

ARAÚJO, Walqueline S., PINHO NETO, Júlio A. S., FREIRE, Gustavo H. A. O uso das mídias sociais pelas bibliotecas universitárias com foco no marketing de relacionamento. Encontros Bibli: revista eletrônica de biblioteconomia e ciência da informação, v. 21, n. 47, p. 2-15, set./dez., 2016.

CINTRA, Flávia Cristina. Marketing digital: a era da tecnologia on-line. Investigação, v. 10, n. 1, p. 6-12, 2010.

DIÓGENES, Fabiene C. B., CUNHA, Murilo B. Desenvolvimento das universidades e bibliotecas universitárias na idade média até à modernidade. Revista Digital

Biblioteconomia e Ciência da Informação, Campinas, v.15, n.1, p. 99-129, jan./abr. 2017.

FUJITA, Mariângela S. L. Aspectos evolutivos das bibliotecas universitárias em ambiente digital na perspectiva da rede de bibliotecas da UNESP. Informação \& Sociedade: Estudos, João Pessoa, v. 15, n. 2, p. 97-112, jul./dez. 2005.

KOTLER, P; BLOOM, P. N. Marketing para serviços profissionais. São Paulo, Atlas, 1988.

LEFÈVRE, F.; LEFÈVRE, A. M. Depoimentos e Discursos: uma proposta de análise em pesquisa social. Brasília: Líber, 2005.

LEFÈVRE, F.; LEFÈVRE, A. M. Discurso do sujeito coletivo: representações sociais e intervenções comunicativas. Texto Contexto Enferm, Florianópolis, v. 23, n. 2, p. 502-507, 2014.

NUNES, Suzana C. CARVALHO, Kátia D. As bibliotecas universitárias em perspectiva histórica: a caminho do desenvolvimento durável. Perspectivas em Ciência da Informação, São Cristóvão, v.21, n.1, p.173-193, jan./mar. 2016.

SILVA, Thiago Leite Amaro; SALCEDO, Diego A. O marketing bibliotecário e a comunicação empresarial. Páginas a\&b: arquivos e bibliotecas, v.3, n.8, p. 23-34, 2017. 